\title{
GEOGRAPHICAL VARIATION OF THE LAW OF THE LARGE NUMBERS AND THE STANDARDIZED MORTALITY RATES
}

\author{
TAKASHI YANAGAWA \\ Department of Mathematics, Kyushu University \\ Fukuoka 812, Japan
}

\begin{abstract}
SUMMARY
In comparing disease rates in a study population with those rates in a general population, the disease rates in the general population are assumed known. Since the size of the general population is very large, this assumption is reasonable by means of the law of the large numbers. Now, when the general population is divided into subpopulations which are called areas, the disease rates in the areas are also assumed known constants by the same law. But these values are variated, as always the case in observational studies. We introduce a superpopulation model to treat this variation and suggest to use this geographical distribution in evaluating, and also in comparing, the Standard Mortality Rates (SMR), an important comparative measure in epidemiology.
\end{abstract}

Key words. cohort study; empirical Bayes estimation; epidemiology

1. 動機と目的

ある特定の集団 П。において、ある疾病（あるいは疾患）D の死亡率が有意に 高度であるかどうかを調べる目的で比較対照集団 П が設定されている場合につい て考えよう。集団 $\Pi （ \Pi 。 ）$ の大きさを $\mathrm{n}\left(n_{0}\right) 、 \Pi （ \Pi \circ ）$ における D に

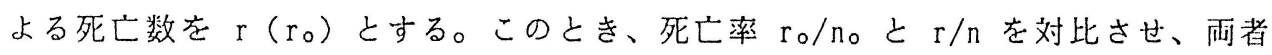
の隔たりの大きさを、一定の確率モデルの下で、確率的に評価するというのが一般 的な統計的考え方である。

比較対照集団 Пとして、日本全国あるいはかなり広範な地域が選ばれることが多 い、つまり $\mathrm{n}$ は極めて大きい。本小諭では $\mathrm{n}$ が極めて大きいとしておく。このと き、すべての既存の統計手法は、川に確率モデルを導入し、 $\mathrm{r}$ を確率变数と考える

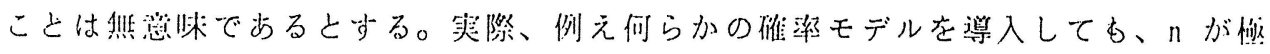
めて大きいので、大数法則によって $\mathrm{r} / \mathrm{n}$ は定数になってしまう。 
ところで、動物実験などとは異なって、ヒトの疾病を対象とする場合、川。と比 較可能な比較対象集団 川 の設定は容易でない。そのため、様々な統計手法が考案 されているが、本小諭では他の一切の煩雑な因子は考虑の枠外におき、Пにおける D の地域分布だけに注目する。近年、コンピュータグラフィックの発展にとむなっ て、種々の疾病の日本全土における地域分布がカラ一刷りで表示さ机るのを目にす る機会が増加したが、それによると地域間バラッキが大变大きい疾病と、そうでな い疾病があることに気付く。つまり、日本全土の死亡率は大数法則によって定数で ある。同じ理由で各県内での死亡率む実質的に定数である。しかしながら、各県間

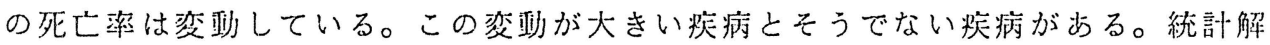
析を行うとき、この変動に配慮しようというのが本小諭の主張である。

\section{2. 基本的な考え方}

$\Pi$ が $k$ 個の部分集団 $\Pi i, i=1,2, \ldots, k$ ，によって

$$
\Pi=\cup \Pi_{i}, \quad \Pi_{i} \cap \Pi_{j}=\phi \quad(i=j)
$$

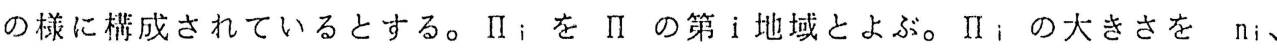
II; でのDによる死亡数を $\mathrm{r} i$ とする。もちろん

$$
\begin{aligned}
& n=n_{1}+n_{2}+\ldots+n_{k} \\
& r=r_{1}+r_{2}+\ldots+r_{k}
\end{aligned}
$$

である。 ni は $n$ より小であるが、こ机む十分大きいとすると $\mathrm{ri}_{\mathrm{i}} / \mathrm{ni}_{\mathrm{i}}$ は定数に近 い。しかしながら、菄団 П が均一でない場合 $\mathrm{r}_{\mathrm{i}} / \mathrm{n}_{i}$ の值は地域間でバラッキが生 じる。

本小論における我々の基本的な考え方は、川。における D の死亡率を評価する とき、従来のように $\mathrm{r} / \mathrm{n}$ を既知として、死亡率 $\mathrm{r}_{0} / \mathrm{n}_{0}$ を $\mathrm{r} / \mathrm{n}$ に対比させるのでは なく、 $r_{0} / n_{0} を ~\left\{r_{1} / n_{1}, r_{2} / n_{2}, \ldots, r_{k} / n_{k}\right\}$ に対比させようというあのである。本 小論では、まげ乎始放として、 $r_{1} / n_{1}, r_{2} / n_{2}, \ldots, r_{k} / n_{k}$ の各々がどの地域からの死 亡率であるかという情報を一切無視する。本来、地域分布の利用は、疾病の地域集 䅡性を見るのがその主目的で占るから、この考え方は奇思な感じを与えるかもし机

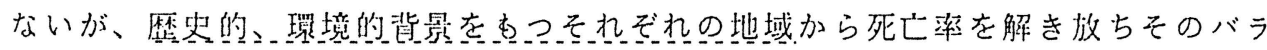
ッキだけに注目しょうというわけである。次の例で、我々の新しい考え方と、従来 
のそれとの違いを明らかにしょう。

例1. 右図のヒストグラムは、1950年度 アメリカ合衆国60-69才白人男性の、アラ スカ、八ワイを除く 49 州の州別肺がん死 亡率の分布である。最小死亡率 $\left(49 \times 10^{-5}\right.$ : New Mexico) と最大死亡率 $\left(224 \times 10^{-5}\right.$ : Nevada）の間でかなり大きくバラッイてい ることが分かる。平均死亡率は $\mathrm{r} / \mathrm{n}=114.5$

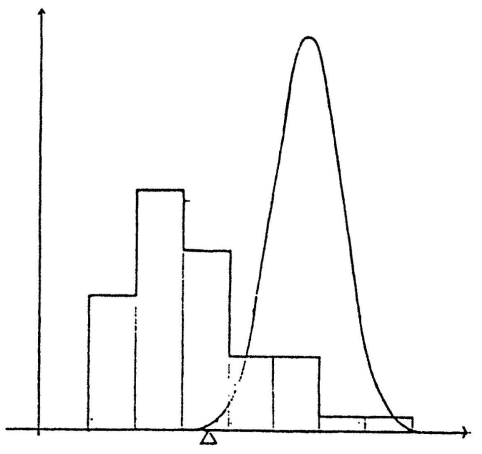
$\times 10^{-5}$ で与えられ、図中 $\triangle$ 印で示されてい る。さて、いま60-69 才白人男性 40,000 人からなる仮想コホートで 68 例の肺がん死亡が観察されたとする。図のなめらか な曲線は $\mathrm{r}_{0} / \mathrm{n}$ 。の分布を正規近似したものである。従来のように、 $\mathrm{r} / \mathrm{n}=114.5$ $\times 10^{-5}$ を既知として、この值と $r_{0} / n_{0}$ を対応させると、図から明らかなように、こ のコホートの肺がん死亡率は有意に大きいと推論される。しかしながら、アラスカ、 八ワイを除く全米の肺がん死亡率の地域分布を考慮すると、図の曲線はヒストグラ ムの筑粗の中にすっぽり含まれてしまう。つまり、地域分有を考虑すると、このコ ホートの扸がん死亡率は有意に大きいとはいえない。

註 1.このコホートが、例えば Montana 州内にあるとする。このとき、比較対照 集団は全米ではなく、Montana 州とすべきではないか、というコメントがあった。 Montana 州の死亡統計から、このコホートデータを抜き出すことが可能ならば、全 米 $\rightarrow$ Montana 州、州 $\rightarrow$ 郡 (county) と置きかえて地域分布を考慮すればよい。ところ で、現実的制約として、これが抜き出せない場合が結構多い。そのため、Montana に隣接するIdahoやWyoming を比較対照集団と定めたり、全米を比較対照集団に 定めたりする。このとき、比較対照集団をどこにとるかによって結果がゆらぐ。こ のように比較対照集団の選択から生じるゆらぎを、地域分布の導入によってとらえ ようというのが本小論の一つの主旨である。

誰 2.上の例では、各州の肺がん死亡率 $\mathrm{r}_{\mathrm{j}} / \mathrm{n}_{\mathrm{j}}$ を定数と考えた。しかしながら、 Nevada 州の該当人口 $\left(n_{j}\right)$ は 6,241，これに対して New York 州のそれは 385,363である。このことから明らかなように個々の死亡率の安定度は州によって大 
きく異なる。以下の定式化では、このことむ考慮されている。

さて、 $r_{0} / n_{0}$ を $\left\{r_{1} / n_{1}, r_{2} / n_{2}, \ldots, r_{k} / n_{k}\right\}$ に対比させるとき問題となる重要な 点が二つある。その一つは、ある地域で $n_{j}$ が小さいとき比 $\mathrm{r}_{\mathrm{j}} / \mathrm{n}_{\mathrm{j}}$ が不安定となり $\left\{\mathrm{r}_{1} / \mathrm{n}_{1}, \mathrm{r}_{2} / \mathrm{n}_{2}, \ldots, \mathrm{rk}_{k} / \mathrm{n}_{k}\right\}$ の中に異常值が含ま㣗てくる可能性があること。残りの 一つ洁、同じ様な問題として、例えば例 1 のような場合、核実験の影響で肺ガン死 亡率が全米のトップになっていると疑われているような Nevada州のような州は $\left.r_{1} / n_{1}, r_{2} / n_{2}, \ldots, r_{k} / n_{k}\right\}$ の中から除いた方がよいのではないかという点である。こ 机らに対して、地域分布のバラッキを四分位点を利用して推定する頑健推定法の利 用等が考えられるが、これらの問題については、他の機会に論じたい。

3. 数学モデル

以上の基本的考え方を次の数学モデルで表現する。

(1) $p_{1} ， p_{2} ， \ldots, p_{k}$ を互いに独立で、同一分布に従う確率变数として、その 平均、分散を

$$
\begin{aligned}
E\left(p_{i}\right) & =\theta \\
V\left(p_{i}\right) & =\alpha \theta \\
\text { とおく。 } & p_{i} \text { に特定の分析估仮定しない。 }
\end{aligned}
$$

（2） pi が所与という条件の下で、 $r_{i}$ は平均 $n_{i} p_{i}$ のポアソン分布に従う

$$
(i=1,2, \ldots, k) \text { 。 }
$$

(3) roは平均nopoのポアソン分布に従う。

いま、（1）、（2）ょり

$$
\begin{aligned}
& E\left(r_{i} / n_{i}\right)=\theta \\
& V\left(r_{i} / n_{i}\right)=\left(\theta / n_{i}\right)+\alpha \theta \quad(i=1,2, \ldots, k)
\end{aligned}
$$

を得る。こ礼より、 $\mathrm{n}_{i} \rightarrow \infty$ のとき $\mathrm{r}_{\mathrm{i}} / \mathrm{n}_{\mathrm{i}}$ の分散は $\mathrm{p}_{\mathrm{i}}$ の分散と一致すること、 従って $\alpha \rightarrow 0$ でない限り $\mathrm{r}_{\mathrm{i}} / \mathrm{n}_{\mathrm{i}}$ 仙定数 $\theta$ と一致しないことが分かる。このこ とから明かなように、 $\alpha$ は死亡㴶の地域間バラッキの大きさを示すパラメー夕、 $\theta$

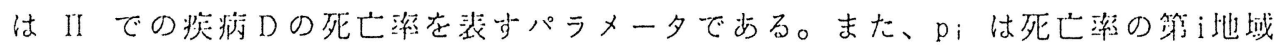

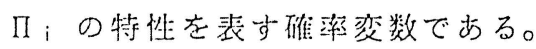


註 3.上のモデルの下では、 $n_{i} \rightarrow \infty$ のとき、 $\mathrm{r}_{\mathrm{i}} / \mathrm{n}_{\mathrm{i}}$ を標準化しても正規分布に法 則収束しない。しかし、 $\Sigma\left(r_{i} / n_{i}\right)$ を標準化すると $k \rightarrow \infty$ のとき正規分布に法則 収束する。

注 4.上のモデルでは、 $\mathrm{r}_{0} / \mathrm{n}_{0}$ と $\left\{\mathrm{r}_{1} / \mathrm{n}_{1}, \mathrm{r}_{2} / \mathrm{n}_{2}, \ldots, \mathrm{rk}_{k} / \mathrm{n}_{k}\right\}$ の独立性を仮定し ている。注 1 で指摘したように、現実的制約のため実際にはこれらが独立でない場 合がひんぱんに生じる。しかしながら、比 $n_{0} /\left(n_{1}+n_{2}+. .++n_{k}\right)$ が十分小さ け狆ば、両者は独立と考えても実際上問題は生じない。

疾病 Dの川。における死亡率が川におけるそれより大きいかどうかは仮説検定 の問題として定式化できるが、ここでは、死亡率の比がいかほど大きいかを見るこ とを㸚らって

$$
p_{0}=\beta \theta
$$

とおき、 $\beta$ の推定問題を考える。 $\beta$ の推定量をEmpirical Bayes 法を適用して次 のように槛成与る。

（i） $\theta$ を既知として $\beta$ の最尤推定量を求める。この推定量は

$$
\left(\mathrm{r}_{0} / \mathrm{n}_{0}\right) / \theta
$$

で与えられる。

(ii) $\theta$ の不偏推定量 $\theta=(\mathrm{r} / \mathrm{n})$ を上式に代入する。かくして $\beta$ の推定量

$$
\left(r_{0} / n_{0}\right) /(r / n)
$$

を得る。

3. 標準化死亡比 ( S M R )

比較対照集団 Пで疾病 Dについて得られる情報は、多くの場合高々、性、および

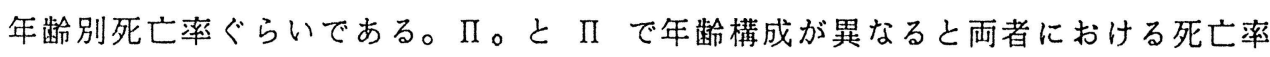
の比較は意味をなさない。年齢調整を行うことが重要である。いま

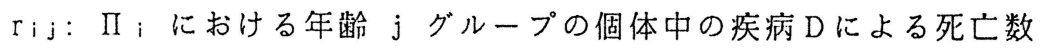

$n_{i j}: \Pi_{i}$ における年齢 $j$ グループの個体数 $(i=0,1, \ldots, k: j=1,2, \ldots, a)$ と㧍き、さらに $\mathrm{p}_{0 \mathrm{j}}=\mathrm{E}\left(\mathrm{r} \mathrm{oj}_{\mathrm{j}} / \mathrm{n}_{\mathrm{oj}}\right)$ ：II での年榆 $\mathrm{j}$ グループに属する個体のDによ る死亡率を表すパラメータを $\theta_{j}$ として 
(*) $\quad p_{\circ j}=\beta \theta_{j}, \quad j=1,2, \ldots, a$

とおいて上と同様に考えると $\beta$ の推定量として

$\operatorname{SMR}=\left(\sum \mathrm{r}_{0 j}\right) / \sum n_{0 j}(\mathrm{r}+\mathrm{j} / \mathrm{n}+\mathrm{j})$

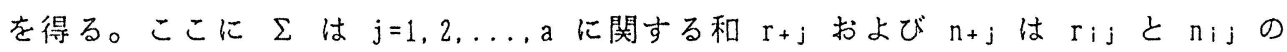
$\mathrm{i}=1,2, \ldots, \mathrm{k}$ に関する和を表す。SMR は標準化死亡比とよばれ、疫学で頻繁に用い ら机る指標である。SMR は1786年にすでに使用されたという報告がある（Keiding、 1987)。よって、200年以上の歴史をむつが、ここでは分母の $\mathrm{r}+\mathrm{j} / \mathrm{n}+\mathrm{j}$ は既知の定数. 上するのではなく、地域分布によるバラッキに支配された確率変数であるとするの が新しい。

註 5.（*）より $\beta=\mathrm{p}_{01} / \theta_{1}=\ldots=\mathrm{p}_{0} \mathrm{a} / \theta_{\mathrm{a}}$ 、従って、数学的に SMR が意味をむつ のは仮定 $\mathrm{po}_{1} / \theta_{1}=\ldots=\mathrm{po}_{\mathrm{a}} / \theta_{\mathrm{a}}$ 。 が満たされるとき、即ちデータがモデル(*)に適合 しているときに限られる。吉村ら(1987)はこの仮定がくずれるとき SMR が意味をな さない場合が歺ることを指摘している。福富・橋本(1990)は現实にはこの仮定が近 似的に成り立つ場合が多いと主張している。実際、SMR が200 年以上にわたって使 用されているという事実は福富・橋本(1990)の主張を支持しているように思われる。 なお、SMR の欠点、特徵等については Breslow-Day (1987) に詳しい。

\section{SMR の最少自乘䛊差}

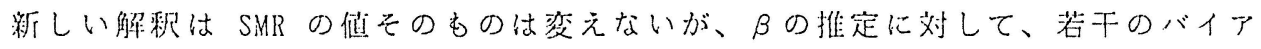
スと一定の分散增加をもたらす。多くの場合、バイアスは微小で無視できる。問題 は分散の增加である。新しい解积、つまり上の数学モデルの下での SMR の最少自乘

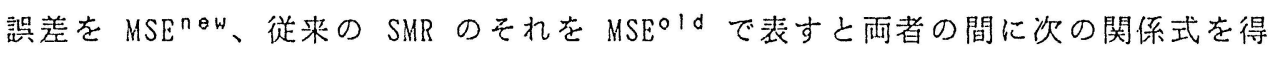
る。

$$
M S E^{\text {new }}=(1+f) M S E^{010}
$$

ただし

$$
\begin{aligned}
& \mathrm{f}=\left(3+\sum_{j=1}{ }^{\mathrm{a}} \mathrm{r}_{0 j}\right) \mathrm{T} \\
& \mathrm{T}=\sum_{j=1^{\mathrm{a}}}\left(n_{0 j} / n_{0+}\right)^{2}\left(\alpha_{j} / \theta_{j}\right) \quad \sum_{i=1}{ }^{k}\left(n_{i j} / n_{+j}\right)^{2}
\end{aligned}
$$

$f$ に含まれるパラメータ $\alpha_{j}, \theta_{j}$ の值は年粈別地域别死亡データからモーメント法 で推定できる。f は常に正で占る。つまり地域分布の導入はSMR の最少自乘誤差を 
(1+f）倍にする。言いかえれば、多くの場合、信頼区間の幅を近似的に $(1+f)^{1 / 2}$ 倍 大きくする。この增加は実質的に意味あるのであるかどうか。意味があるのなら、

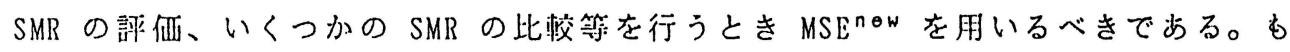
し意味なけ机ば地域分布の考慮は無意味である。以下、具体例で $\mathrm{f}$ が実質的に無視 出来ない場合があることを示す。

5. 例

表 1 は米国モンタナ州のある銅精錬所に 1 年以上従業した男子労働者 8.047 人を 1938年から 1977年まで追跡調查して得られた肺がんによる死亡の様子をまとめた むのである。BreslowーDayの本(1987)から引用した。 この肺がん死亡率はアラスカ、ハワイを除く米国全土 表 1 肺がん死亡数 のそれと比べて何倍ほど大きいのか、その大きさは（モンタナ州銅精鍊所） p 值でみればどれほどなのか、というのが問題である。 表 2 は 1950 年と 1970 年を基準年として評価したとき の $\mathrm{f}$ の推定值を示したすのである。本来なら 1938年 年齢 該当人口 死亡数 から 1977 年までの各州年路性別肺がん死亡数、および $40-49 \quad 49,363 \quad 21$ 人口を利用すべきであるが、地域分布の影響を大ざっ $50-59 \quad 41,811 \quad 80$ ぱに見積ることを目的として 1950年と1970年のそれ $60-69 \quad 24.394 \quad 117$ $70-79 \quad 9,423 \quad 276$ ぞれを代表年として利用した。表 2 より $\mathrm{f}$ の最大值は 1950年を基準年としたとき年齢 60-69才のグループによって0.40で与えられる。 つまり、地域分布は分散を $40 \%$ 増加させる。また、SMR に対しては $\mathrm{f}=0.28$ (1950 年)、0.13（1970年）で与えれる。この結果、SMR を評仙するとき地域分布が本質的 影響を与える場合がありえることが実証的に示された。

表 2 f の推定値

$\begin{array}{llllllc}\text { 年齢 } & & 40-49 & 50-59 & 60-69 & 70-79 & \text { SMR } \\ \text { 基準年 } & 1950 & 0.045 & 0.219 & 0.399 & 0.231 & 0.280 \\ & 1970 & 0.031 & 0.078 & 0.235 & 0.052 & 0.127\end{array}$


6.まとめ

死亡率は地域間でバラッキがある。従来、標準化死亡比 (SMR) などの分母は 定数と考えられてきたが、地域間バラツキを考慮すると単純に定数とは考えられな い。本小論では、数学モデルを導入して、地域分布による分母のバラッキを評価し た。さらに、実際例で、このバラッキが S M R の評価に本質的影響を与える場合が あることを示した。この結果、SMRを用いる㭘定などのより複雑な統計手法に対 して、地域分布の影響を考虑にいれた榆定法の開発等に関する研究が、今後の新し い研究課題として明示された。

\section{References}

Breslow, N.E. and Day, N.E. (1987): STATISTICAL METHODS IN CANCER

RESEARCH: Vol 2 - THE DESIGN AND ANALYSIS OF COHORT STUDIES, IARC

Scientific Publication No.82, International Agency for Research on Cancer, Lyon

Keiding. N. (1987): The methods of expected number of deaths, 1786-18861986. International Statist Review 55, 1-20.

吉村健清、池田正人、三苫むつ子、重松峻夫（1987）：標準化死亡比（SMR）の妥 当性の検討、第46回日本公衆衛生学会総会 (長崎) 抄録集、10.

福富和夫、橋本修二(1989)：標準化死亡比に関する考察、日本公衛誌、第36卷第3号、 平成元年3月15日、155-159.

[Received June, 1990] 